\title{
PREVALENCE OF JUVENILE IDIOPATHIC ARTHRITIS IN SCHOOLCHILDREN FROM THE CITY OF SAO PAULO, THE LARGEST CITY IN LATIN AMERICA
}

Vania Schinzel (UNIFESP, São Paulo, SP, Brasil), Simone Guerra Lopes da Silva (UNIFESP, São Paulo, SP, Brasil), Giovana Paludo (UNIFESP, São Paulo, SP, Brasil), Aline Rocha (UNIFESP, São Paulo, SP, Brasil), Cláudio Arnaldo Len (UNIFESP, São Paulo, SP, Brasil), Maria Teresa de Sande e Lemos Ramos Ascensão Terreri (UNIFESP, São Paulo, SP, Brasil)

\section{BACKGROUND}

Juvenile idiopathic arthritis (JIA) is a chronic inflammatory disease that affects children and adolescents. Its prevalence varies greatly from one study to another according to the population and methodology. Some tools may be helpful in screening for suspected cases. The aim of this study is determine the prevalence of JIA in children and adolescent students in the city of São Paulo, Brazil.

\section{MATERIALS AND METHODS}

This cross-sectional study was conducted from March 2016 to November 2017. It was based on a populational study envolving school children and adolescents from São Paulo, the largest city of Brazil. We randomly selected students under 16 years old from private schools with more than 1000 students who were evaluated through a specific questionnaire for screening suspected cases of chronic arthropathy (Early Diagnosis of Chronic Arthritis - 12 items - EDA-12) and subsequent anamnesis and rheumatologic physical examination for diagnostic confirmation.

\section{RESULTS}

We contacted all 79 schools in the universe, of which $12(15,18 \%)$ agreed to participate in the study. A total of 21,119 questionnaires were handed out to the parents. We obtained a response of 5,710 (27\%). In 108 cases the EDA-12 score was considered positive $(\geq 5)$. We examined all these 108 "suspicious" children. In 10 cases, the rheumatologic evaluation confirmed the diagnosis of arthritis, since the subjects presented a history and physical examination compatible with JIA. The prevalence of JIA in children and adolescents was $0.196 \%(95 \% \mathrm{Cl}=0.104 \%-0.371 \%)$.

\section{CONCLUSION}

In this first Brazilian population study to evaluate the prevalence of JIA, we observed that the disease is relatively prevalent in our country (196 / 100.000 children), which is similar to that observed in other studies involving children from urban centers. 